\title{
No effect on performance tests from a neuromuscular warm-up programme in youth female football: a randomised controlled trial
}

\author{
Hanna Lindblom, Markus Waldén and Martin Hägglund
}

\section{Linköping University Post Print}

N.B.: When citing this work, cite the original article.

The original publication is available at www.springerlink.com:

Hanna Lindblom, Markus Waldén and Martin Hägglund, No effect on performance tests from a neuromuscular warm-up programme in youth female football: a randomised controlled trial, 2012, Knee Surgery, Sports Traumatology, Arthroscopy, (20), 10, 2112-2119.

http://dx.doi.org/10.1007/s00167-011-1846-9

Copyright: Springer Verlag (Germany) http://www.springerlink.com/?MUD=MP

Postprint available at: Linköping University Electronic Press http://urn.kb.se/resolve?urn=urn:nbn:se:liu:diva-84893 
No effect on performance tests from a neuromuscular warm-up programme in youth female football: a randomised controlled trial

Hanna Lindblom, $\mathrm{PT}, \mathrm{MSc}^{1}$; Markus Waldén, $\mathrm{MD}, \mathrm{PhD}^{2}$; Martin Hägglund, $\mathrm{PT}, \mathrm{PhD}^{1}$

${ }^{1}$ Division of Physiotherapy, Department of Medical and Health Sciences, Linköping University, Linköping, Sweden. ${ }^{2}$ Department of Orthopaedics, Hässleholm-KristianstadYstad Hospitals, Hässleholm, Sweden; Division of Community Medicine, Department of Medical and Health Sciences, Linköping University, Linköping, Sweden.

Address correspondence to:

Ms. Hanna Lindblom

Department of Medical and Health Sciences

Division of Physiotherapy

Linköping University

SE-581 83 Linköping

Sweden

E-mail: lindblom.hanna@bredband.net 


\begin{abstract}
Purpose The objective of the present randomised controlled trial was to study the effect of a neuromuscular warm-up programme on performance tests in youth female football.

Methods Four youth female football teams with players aged 12-16 years were randomised into an intervention group and control group. The intervention was a 15-minute neuromuscular warm-up program carried out twice a week during the 11-week study period. Baseline and follow-up measurements of performance were made indoors and included the star excursion balance test, a countermovement jump test, a triple-hop for distance test, a modified Illinois agility test, and 10 and $20 \mathrm{~m}$ sprint tests.

Results Fifty-two players (intervention 28; control 24) took part in baseline measurements, and after dropout, 41 players (intervention 23; control 18) were included for analysis. Minor positive changes were seen in the control group compared to the intervention group for a subscore of the star excursion balance test $(P<0.05)$ and in the modified Illinois agility test $(P<$ 0.05). No improvement was seen in the intervention group from baseline to follow-up. Conclusions The study showed that a neuromuscular warm-up programme carried out during 11 weeks did not improve performance in youth female football. This could indicate that the programme does not contain sufficient stimulus to improve performance. A low player attendance at training sessions, and low specificity between exercises in the warm-up programme and the evaluated performance tests may also contribute to the lack of effect. Level of evidence $\mathrm{I}$.
\end{abstract}

Keywords Adolescent, Knee, Injuries, Prevention, Soccer 


\section{INTRODUCTION}

Female football (soccer) players are more susceptible to anterior cruciate ligament (ACL) injury compared to their male counterparts and they are also younger than male players when sustaining an ACL injury [20]. Several neuromuscular training programmes have therefore been evaluated to prevent acute knee injury, ACL injury in particular, among youth female football players $[8,9,11,13,16]$.

A neuromuscular training programme was developed by experienced physiotherapists from different sports federations and organisations in Sweden 2005 and is intended to be used primarily in players 12 to 16 years of age. In a recent study, the effect of the programme on reducing the ACL injury rate in youth female football was investigated, [7] but its effect on performance enhancement has not been evaluated. It is similar to other neuromuscular programmes, including type of exercises, training volume and training frequency, such as the Federation of International Football Associations (FIFA) “11” programme [17], and the Santa Monica "Prevent Injury Enhance Performance" (PEP) programme [19], that have been evaluated both from injury prevention and performance enhancement perspectives.

There are contradictory findings regarding the effect that neuromuscular programmes may have in improving physical performance [6]. Performance in football is dependent on technical, tactical and physical skills [10], and due to its complexity it is difficult to evaluate performance for football players in a valid and reliable way $[1,18]$. Nevertheless, some studies have shown improvements in performance aspects relevant for football players (e.g. balance, power, sprinting, jump height etc.) from neuromuscular training programmes [2, 12], while two other studies showed no effects $[17,19]$. 
The objective of this study was to evaluate the effect of the Swedish neuromuscular warm-up programme on different performance tests in youth female football. Our hypothesis was that improvements in performance would be evident in the intervention group following 11 weeks of training. 


\section{MATERIALS AND METHODS}

\section{Study design}

The study was a randomised controlled trial (RCT) where teams were block randomised two and two to achieve equal numbers of participants and equal age distribution in the intervention and the control groups. The randomisation was performed by a blinded statistician.

The study was carried out for 11 weeks during the spring competitive season between March and June 2010 in Linköping, Sweden. The coaches provided their respective teams with detailed information about the study procedure. Anthropometric data and information about previous injuries, present physical complaints, previous experience in football, and participation in other regular physical activities outside football were collected in a baseline questionnaire. The players' attendance to training and matches were recorded by the coaches on an exposure form [7]. Injuries that occurred during the study period were reported to one of the authors (HL).

\section{Participants}

Four youth female football teams with players aged 12-16 years $(n=73)$ were approached for recruitment. Teams reported that they did not perform any standardised neuromuscular training program similar to the planned intervention. For inclusion players had to be physically healthy and able to participate with maximum effort during testing. Players with an injury or disease preventing them from participating fully in the testing sessions were excluded. Twenty-one players did not attend baseline measurements due to exclusion criteria or being unavailable on the test day. Thus, 52 players (intervention 28; control 24) took part 
in baseline measurements (Fig. 1). Eleven players (intervention 5; control 6) were lost to follow-up due to injury, illness or other commitments (Fig. 1). Player characteristics in the two groups were comparable (Table 1).

\section{Intervention}

The neuromuscular warm-up programme (Knäkontroll, SISU Idrottsböcker ${ }^{\odot}, 2005$ ) contains six exercises targeting core stability, balance, landing technique, and proper knee alignment. Each exercise has four different levels of difficulty and one corresponding pair exercise. The exercises are: (1) one-legged knee squat, (2) pelvic lift, (3) two-legged knee squat, (4) the bench, (5) the lunge, and (6) jump/landing. All players start at the lowest level of difficulty and the exercises are intensified individually as the player improves her performance and is able to perform the exercises correctly as assessed by the coach. After familiarisation the programme takes about 15 minutes to complete. A complete description of the programme has recently been published in a study protocol for a randomised controlled trial where the preventive effect on acute knee injury is evaluated [7].

All players and coaches were instructed by one author (HL) how to carry out the exercises on a practical education meeting. The coaches were also given instruction leaflets and a CDROM with the exercises. The same author also made one unannounced visit to the teams in the intervention group to ensure good compliance with the programme and to observe and correct any training errors. The execution of the neuromuscular warm-up programme was also registered by the coaches on the exposure form. The intervention group was instructed to carry out the neuromuscular warm-up programme twice a week during the intervention period, since this is the standard weekly training frequency for teams in this age group. The control group was instructed to perform its usual football training without any changes. 


\section{Testing procedures}

Testing was performed indoors in the same venue and at the same time of the day at baseline and follow-up testing since test results may vary during the day [5]. The testing order of the players was the same during all tests. Approximately two to three minutes of rest was allowed between all test trials except for the star excursion balance test (SEBT) where one player was tested at a time. Indoor shoes were used in all tests and the participants were instructed to use the same shoes at the baseline and follow-up tests. Before testing, a standardised 10-minute football warm-up with running and skipping exercises was performed. Neither static nor dynamic stretching was performed since these might affect performance negatively [14]. All players were asked to refrain from physical exhaustion on the day before testing. To assure good attendance all players were sent reminders via e-mail one to three days prior to the testing.

First, balance was tested with the SEBT in the anterior, posteromedial and posterolateral directions (Fig. 2). The results were normalized according to leg length [4]. The leg length was measured with a cloth measure with the player in supine position from the anterior superior iliac spine to the centre of the medial malleolus. The subject was standing in the middle of the star and reached as far as possible in three different directions and lightly touched the ground before returning to the standing position. The hands were held at the iliac crest during the whole test. A mark was made on the ground where the toes touched the floor and the distance was measured with a cloth measure. If the player failed to keep her balance the test was repeated. After performing a thorough practice trial with six attempts in each direction to overcome learning effects [4], three test trials in each direction were performed. Measures were normalised according to the formula "test value/leg length x 100". A 
composite score was calculated for each leg by computing the average of the three normalised measurements in the different directions. The intraclass correlation (ICC) coefficients for the SEBT ranged between 0.63-0.77 when calculated for each direction, and for the composite score 0.71 (95\% confidence interval (CI) $0.41,0.85)$ and 0.80 (95\% CI $0.60,0.90)$ for the right and left leg, respectively.

Next, a countermovement jump (CMJ) test was performed to measure vertical jump height. The jumps were performed with the hands on the hips during the entire jump and without an overhead goal. An infrared contact mat was used to calculate flight time, which is converted to jumping height (MuscleLab 4010, Ergotest Technology a.s., Norway). Two practice jumps were allowed before the three test jumps. The ICC for the CMJ was 0.91 (95\% CI 0.87, 0.95).

Then the triple-hop for distance test, originally developed to assess lower limb asymmetries [15], was performed to measure horizontal jump length in a similar way as Kilding et al. [12]. The players alternated between jumping on the right and the left leg and always started with the dominant leg (preferred kicking leg). From a one leg standing starting position the player jumped forward and landed on the same leg, jumped forward and landed on the other leg, and jumped for the third time and landed on both legs. Free arm and leg swinging was permitted. If the test player lost her balance upon landing the test trial was repeated. The distance was measured from the starting line to the place where the rear heel landed after the last hop. Two practice trials were performed before the three test trials. The ICC for the triple-hop test was $0.90(95 \%$ CI $0.83,0.94)$.

After that players carried out a modified Illinois agility test in a test course that was 10 meters long and 5 meters wide (Fig.3). The test started with the player standing with one foot in 
front of the other at the starting line, and at command the player sprinted through the course. When turning after the first 10 meter sprint, and again prior to the last 10 meter sprint to the finish line, the player touched the ground with one hand to ensure that the line was crossed. The test was modified from the original test, where athletes start the test lying face down with the hands at shoulder level, and do not touch the ground at any time. Running time was measured with timing gates using photoelectric cells (MuscleLab 4010, Ergotest Technology a.s., Norway) positioned at the start and the finish line. One practice trial with light jogging was allowed before the two test trials. The ICC for the modified Illinois agility test was 0.89 $(95 \%$ CI $0.74,0.95)$.

Finally, sprinting performance over 10 and $20 \mathrm{~m}$ was tested. The sprinting was recorded from a standing start and started at the assessors' command. Timing gates with photoelectric cells (MuscleLab 4010, Ergotest Technology a.s., Norway) were placed at the start, after 10 and 20 m. One practice trial and two test trials were performed. The ICC for the 10 and $20 \mathrm{~m}$ sprints were 0.85 (95\% CI $0.50,0.94)$ and 0.94 (95\% CI 0.44, 0.98), respectively.

Except for SEBT, where the primary author (HL) was responsible for testing, the test leader conducting all other measurements was blinded to the players' group allocation and did not take any further part in the study.

\section{Ethics}

The study was approved by the regional ethical review board in Linköping (M 197-08). The players and parents/guardians gave written informed consent.

\section{Statistical analysis}


A pre-trial sample-size calculation showed that 42 subjects ( 21 in each group) were necessary to determine a difference of $10 \%$ on the countermovement jump test (absolute change 2.8 $\mathrm{cm}$ ) between groups at an alpha level of 0.05 and to reach $80 \%$ power based on the results (mean $27.9 \mathrm{~cm}$ ) in a previous study in a similar setting [17].

The groups were compared at baseline using the independent samples t-test or the MannWhitney U-test depending on the test variables. The independent samples t-test was used for between-group comparisons of the absolute change in scores between baseline and follow-up measurements according to intention to treat. The paired samples t-test was used for withingroup comparisons between baseline and follow-up. The best results from the different performance tests were used for analyses. Drop-out analysis was performed with independent samples t-test and Mann-Whitney U-test. ICC coefficients values were calculated including all test trials (range two to three for the various tests) from baseline measurements for all testing variables using a two way random effects model and an absolute agreement definition. Results are reported as means \pm standard deviation (SD) and the between-group and withingroup changes are given as means with a corresponding 95\% CI. Statistical analyses were conducted in SPSS version 15.0 (SPSS Inc, Chicago, Illinois, USA). The two-sided level of significance was set at $P \leq 0.05$. 


\section{RESULTS}

\section{Effect of intervention on performance measures}

No significant effect of the intervention was found for any of the performance measures. Between-group comparisons showed significant changes between baseline and follow-up measurements for sub-scores of the SEBT and the Illinois agility test favouring the control group (Table 2). Within-group comparisons showed no significant improvements in the intervention group after the intervention period (Table 2).

\section{Compliance with the warm-up program}

The two intervention teams carried out the neuromuscular warm-up programme in 18 of 18 training sessions and 20 of 21 training sessions, respectively. However, due to low mean player attendance at training sessions $(59.6 \pm 14.3 \%)$, the average player completed only 11.2 \pm 2.7 sessions with the warm-up programme. No injuries or other inconveniences were reported during or after performing the neuromuscular warm-up programme.

\section{Baseline characteristics and exposures}

A drop-out analysis showed no differences between drop-outs and participants for baseline characteristics other than that drop-outs had a higher rate of previous injury (7/11 vs. 10/41, $P$ $=0.015)$. Players in the control group had more training $(28.6 \pm 10.5$ vs. $18.2 \pm 4.5$ hours, $P=$ $0.001)$ and match exposure $(7.9 \pm 3.0$ vs. $6.4 \pm 3.4$ hours, $P=0.14)$ during the study period. 


\section{DISCUSSION}

The principal finding of this randomised trial was that no performance improvements were seen after introducing a neuromuscular warm-up programme in female youth football players. Our results are in agreement with two previous studies in girls' football that both failed to show any performance improvements from "the 11" [17], and the PEP [19]. In contrast, two other studies showed positive effects on performance from similar neuromuscular training programmes $[2,12]$. In the study by Kilding et al. [12], improvements ranging between $2 \%$ and $6 \%$ was reported in boys' football for the countermovement jump, triple hop for distance, and $20 \mathrm{~m}$ sprint tests with a slightly modified "11" program. DiStefano et al. [2] also showed significant improvements in balance, evaluated as time-to-stabilization, and vertical jump height in a study comprising both boys and girls. In the study by Vescovi \& VanHeest [19], only transient improvements in sprint times were seen following 6 weeks of training with the PEP programme, while no improvements were evident after 12 weeks.

There are several possible explanations for the lack of effect on performance in youth football observed in our and some previous studies. First, the two studies showing performance improvements have been conducted in subjects below 12 years, most of them probably prepubertal $[2,12]$, whereas the studies showing no effects have included teenagers up to 18 years $[17,19]$, thus including mainly pubertal and post-pubertal girls, similar to the present study. Hence, it is possible that the exercises included in the present and other neuromuscular warm-up programmes are not demanding enough to improve performance in pubertal and post-pubertal teenagers who might need conditioning programmes with higher load and intensity to benefit from the training [9]. 
Second, differences in dosage might be another factor that needs to be taken into account. All neuromuscular warm-up programmes evaluated in the literature take less than 25 minutes to complete, but the recommended frequency differs between studies as well as the length of the intervention period. We instructed teams to carry out the neuromuscular warm-up programme twice a week as recommended by the developers of the programme [7]. In addition, teams in our studied age group rarely have more than two coach-directed training sessions per week and it was therefore not feasible to introduce more than two warm-up sessions per week in the study design. This training frequency is, however, lower than in the two studies showing significant effects where the recommended training frequency was five [12] and three [2] times per week, respectively. Thus, sufficient stimulus may not have been achieved to improve performance with our programme. Still, previous studies showing no performance improving effects also had three intervention sessions per week $[17,19]$, suggesting that frequency alone does not explain this discrepancy in findings. The length of the intervention period in our study was eleven weeks which in fact is in the higher range of previous studies where intervention have lasted from six to twelve weeks $[2,12,17,19]$. However, due to a lower weekly recommended training dose, the total number of warm-up sessions scheduled for the intervention teams in our study (18 and 21 , respectively) was lower compared to the previous studies in the field where the maximum training amount ranged from 27 to 36 sessions $[2,12,17,19]$.

Third, the player execution of the present programme was lower than in all previous studies $(72-92 \%)[2,12,17,19]$. It should be noted, however, that the low player execution of the programme was completely due to players being absent from training while the intervention group teams in fact carried out the warm-up sessions according to instructions (38 of 39 training sessions). 
Fourth, no standard tests exist that truly correlates with the performance during football play and the internal validity of performance studies may thus be limited [1]. The performance test battery chosen for the present study were similar to many of the tests used in previous studies to facilitate comparison $[12,17,19]$. However, it can be argued that there is low resemblance between the neuromuscular warm-up exercises carried out and the evaluated performance tests. For example, the exercises in our neuromuscular warm-up programme were generally carried out at slow speeds while four out of five performance tests included high speed components. Only the SEBT closely resembles one of the exercises in our neuromuscular warm-up programme. Still, we found no improvements in SEBT from our intervention, unlike another study where significant improvements in the posterolateral and posteromedial directions were seen in youth female football players after an 8-week neuromuscular training programme [3]. Plyometric exercises were included in other similar neuromuscular programmes $[2,9,12,17,19]$ but not in ours, and it is more likely that an improvement in jumping or sprinting performance would have been achieved if a plyometric training component was included. However, there is no clear trend in the literature about the effect of adding plyometrics, where two of the previous studies showed improvements in jumping ability $[2,12]$, and two reported no effects $[17,19]$. The agility test used in the present study requires rapid change of directions during running, and no such exercises were included in our neuromuscular programme. The instructions in the warm-up programme were to carry out exercises at slow speeds with focus on proper control and alignment of the core, hip, knee and foot. In addition, the jump/landing exercises in the programme focused on reducing landing forces rather than on explosive qualities. The design and recommended execution of our neuromuscular programme may thus have had less impact on performance at high speed. 
It should be stressed that even if the neuromuscular warm-up programme did not have any direct performance increasing effects, as evaluated in the present trial, it could still have indirect enhancement effects on football-relevant performance provided that the programme may prevent injuries [7]. By avoiding injury players can train properly and thus develop and improve their football performance without interruptions and decreases in fitness attributable to injury.

\section{Methodological considerations}

An obvious strength of our study was the blinded assessor during measurements and the testing equipment with photoelectric cells that were used in order to make the measurements more objective and less prone to bias. All players were also allowed practice trials to minimise learning effects and the ICC coefficients for all tests, except the SEBT, showed excellent agreement which further emphasises the stability of the measurements.

Additionally, player training and match attendance was reported individually for all training and matches making it possible to monitor both team and player compliance properly.

The main limitation of the trial is the low number of actual warm-up sessions carried out by players, owing to a low training attendance of players and a lower maximum number of scheduled training sessions than in previous studies, even though teams executed the programme as intended. Another limitation is that the control group had a greater exposure to training and match play and the improvements seen for some of the test variables in the control teams may thus be a result of more intense football training. However, although this difference in training and match exposure may interfere with between-group comparisons, the within-group comparison between baseline and follow-up in the intervention group did not show any significant improvement for any variable. Control group teams were instructed to 
continue their usual training without any changes but we did not monitor whether they implemented similar exercises as the intervention group during the study period, e.g. by using unannounced visits such as in the intervention group, and this is another limitation of our study. Next, the pre-trial sample size calculation showed a necessary 42 subjects, while we had only 41 remaining players for the analyses. Another two players were excluded from sprint tests and the modified Illinois agility test at follow-up measurements due to pain while carrying out the tests. However, we expect no type II error since not even a trend towards improvement was seen in the intervention group. Importantly, our sample is also within the range of previous studies (24-65 players) [2, 12, 17, 19].

\section{Conclusions}

A neuromuscular warm-up programme carried out during an 11-week intervention period did not improve performance parameters in youth female football players. This could indicate that the programme does not contain sufficient stimulus to improve performance. A low player attendance at training sessions, and low specificity between exercises in the warm-up programme and the evaluated performance tests may also contribute to the lack of effect. 


\section{ACKNOWLEDGEMENTS}

The authors would like to thank all coaches and players who participated in the trial, Fredrik Wandus for assistance with test measurements, and Henrik Magnusson, MSc, for assistance with data setup.

The study was supported by grants from the Swedish Football Association and the Swedish National Centre for Research in Sports.

\section{CONFLICT OF INTEREST}

MW and MH are employed by the Swedish Football Association for constituting the medical staff of the male under-19 national team. No other conflict of interest relevant to this article was reported. 


\section{REFERENCES}

1. Currell K, Jeukendrup AE (2008) Validity, reliability and sensitivity of measures of sporting performance. Sports Med 38:297-316

2. DiStefano LJ, Padua DA, Blackburn JT, Garrett WE, Guskiewicz KM, Marshall SW (2010) Integrated injury prevention programme improves balance and vertical jump height in children. J Strength Cond Res 24:332-342

3. Filipa A, Byrnes R, Paterno MV, Myer GD, Hewett TE (2010) Neuromuscular training improves performance on the Star Excursion Balance Test in young female athletes. J Orthop Sports Phys Ther 40:551-558

4. Gribble PA, Hertel J (2003) Considerations for normalizing measures of the Star Excursion Balance Test. Meas Phys Educ Exerc Sci 7:89-100

5. Gribble PA, Tucker WS, White PA (2007) Time-of-day influences on static and dynamic postural control. J Athl Train 42:35-41

6. Griffin LY, Albohm MJ, Arendt EA, Bahr R, Beynnon BD, Demaio M, Dick RW, Engebretsen L, Garrett WE Jr, Hannafin JA, Hewett TE, Huston LJ, Ireland ML, Johnson RJ, Lephart S, Mandelbaum BR, Mann BJ, Marks PH, Marshall SW, Myklebust G, Noyes FR, Powers C, Shields C Jr, Shultz SJ, Silvers H, Slauterbeck J, Taylor DC, Teitz CC, Wojtys EM, Yu B (2006) Understanding and preventing noncontact anterior cruciate ligament 
injuries - a review of the Hunt Valley II Meeting, January 2005. Am J Sports Med 34:15121532

7. Hägglund M, Waldén M, Atroshi I (2009) Preventing knee injuries in adolescent female football players - design of a cluster randomized controlled trial. BMC Musculoskelet Disord $10: 75$

8. Heidt RS, Sweeterman LM, Carlonas RL, Traub JA, Tekulve FX (2000) Avoidance of soccer injuries with preseason conditioning. Am J Sports Med 28:659-662

9. Hewett TE, Lindenfeld TN, Riccobene JV, Noyes FR (1999) The effects of neuromuscular training on the incidence of knee injury in female athletes. Am J Sports Med 27:699-706

10. Hoff J, Helgerud J (2004) Endurance and strength training for soccer players physiological considerations. Sports Med 34:165-180

11. Kiani A, Hellquist E, Ahlqvist K, Michaëlsson K, Byberg L (2010) Prevention of soccerrelated knee injuries in teenaged girls. Arch Intern Med 170:43-49

12. Kilding AE, Tunstall H, Kuzmic D (2008) Suitability of FIFA's “The 11" training programme for young football players - impact on physical performance. J Sports Sci Med $7: 320-326$

13. Mandelbaum BR, Silvers HJ, Watanabe DS, Knarr JF, Thomas SD, Griffin LY, Kirkendall DT, Garrett W Jr (2005) Effectiveness of a neuromuscular and proprioceptive 
training program in prevention anterior cruciate ligament injuries in female athletes. Am $\mathbf{J}$ Sports Med 33:1003-1010

14. Needham RA, Morse CI, Degens H (2009) The acute effect of different warm-up protocols on anaerobic performance in elite youth soccer players. J Strength Cond Res $23: 2614-2620$

15. Noyes FR, Barber SD, Mangine RE (1991) Abnormal lower limb symmetry determined by function hop tests after anterior cruciate ligament rupture. Am J Sports Med 19:513-518

16. Pfeiffer RP, Shea KG, Roberts D, Grandstrand S, Bond L (2006) Lack of effect of a knee ligament injury prevention program on the incidence of noncontact anterior cruciate ligament injury. J Bone Joint Surg Am 88:1769-1774

17. Steffen K, Bakka HM, Myklebust G, Bahr R (2008) Performance aspects of an injury prevention program: a ten-week intervention in adolescent female football players. Scand J Med Sci Sports 18:596-604

18. Stølen T, Chamari K, Castagna C, Wisløff U (2005) Physiology of soccer - an update. Sports Med 35:501-536

19. Vescovi JD, VanHeest JL (2010) Effects of an anterior cruciate ligament injury prevention program on performance in adolescent female soccer players. Scand J Med Sci Sports 20:394-402 
20. Waldén M, Hägglund M, Magnusson H, Ekstrand J (2011) Anterior cruciate ligament injury in elite football: a prospective three-cohort study. Knee Surg Sports Traumatol Arthrosc 19:11-19 


\section{TABLES}

Table 1 Demographics

\begin{tabular}{lll}
\hline & Intervention group $(\mathrm{n}=23)$ & Control group $(\mathrm{n}=18)$ \\
\hline Age $(\mathrm{yrs})$ & $14.2 \pm 0.7$ & $14.2 \pm 1.1$ \\
Stature $(\mathrm{cm})$ & $165.0 \pm 6.5$ & $164.2 \pm 6.1$ \\
Body mass $(\mathrm{kg})$ & $53.9 \pm 8.6$ & $51.6 \pm 7.4$ \\
Football experience (yrs) & $7.6 \pm 1.6$ & $6.9 \pm 2.2$ \\
Additional sports activity & $12(52 \%)$ & $8(44 \%)$ \\
Previous injury & $4(17 \%)$ & $6(33 \%)$ \\
Current complaints & $7(30 \%)$ & $6(33 \%)$ \\
\hline
\end{tabular}

Values are mean \pm standard deviation or number of players and (\%). 
Table 2 Results of baseline and follow-up tests, within groups $(\Delta \mathrm{W})$ differences between baseline and follow-up, and between-group differences in change between baseline and follow-up $(\Delta \mathrm{B})$.

\begin{tabular}{|c|c|c|c|c|c|c|c|}
\hline & \multicolumn{3}{|c|}{ Intervention group $(\mathrm{n}=23)$} & \multicolumn{3}{|c|}{ Control group $(\mathrm{n}=18)$} & \multirow[b]{2}{*}{$\Delta \mathrm{B}(95 \% \mathrm{CI})$} \\
\hline & Baseline & Follow-up & $\Delta \mathrm{W}(95 \% \mathrm{CI})$ & Baseline & Follow-up & $\Delta \mathrm{W}(95 \% \mathrm{CI})$ & \\
\hline \multicolumn{8}{|l|}{ Star excursion balance test $(\mathrm{cm})$} \\
\hline right posterolateral & $115.3 \pm 9.8$ & $116.2 \pm 9.1$ & $0.9(-2.5,4.3)$ & $111.4 \pm 8.5$ & $116.7 \pm 10.2$ & $5.3(1.9,8.7)^{*}$ & $-4.3(-9.1,0.5)$ \\
\hline right posteromedial & $110.6 \pm 9.3$ & $111.0 \pm 8.4$ & $0.4(-2.8,3.5)$ & $106.9 \pm 7.4$ & $110.5 \pm 9.2$ & $3.6(0.4,6.8)^{*}$ & $-3.2(-7.6,1.3)$ \\
\hline right anterior & $101.2 \pm 7.2$ & $99.6 \pm 7.6$ & $-1.6(-3.5,0.2)$ & $98.3 \pm 8.1$ & $96.9 \pm 6.6$ & $-1.4(-4.4,1.6)$ & $-0.2(-3.5,3.1)$ \\
\hline left posterolateral & $118.7 \pm 10.4$ & $115.9 \pm 9.0$ & $-2.8(-6.2,0.6)$ & $113.8 \pm 8.4$ & $116.1 \pm 9.4$ & $2.2(-2.2,6.6)$ & $-5.1(-10.4,0.2)$ \\
\hline left posteromedial & $109.6 \pm 9.2$ & $110.5 \pm 7.7$ & $0.9(-2.2,4.0)$ & $106.1 \pm 6.6$ & $112.0 \pm 9.6$ & $5.9(2.5,9.2)^{*}$ & $-5.1(-9.6,-0.6)^{*}$ \\
\hline left anterior & $101.0 \pm 7.1$ & $98.7 \pm 5.5$ & $-2.3(-4.9,0.4)$ & $98.6 \pm 8.5$ & $99.3 \pm 7.9$ & $0.7(-2.9,4.3)$ & $-3.1(-7.3,1.2)$ \\
\hline composite score right & $109.0 \pm 8.0$ & $108.9 \pm 7.4$ & $-0.1(-2.4,2.2)$ & $105.5 \pm 7.3$ & $108.0 \pm 7.8$ & $2.5(0.4,4.6)^{*}$ & $-2.6(-5.7,0.6)$ \\
\hline composite score left & $109.8 \pm 7.9$ & $108.4 \pm 6.6$ & $-1.4(-3.5,0.7)$ & $106.2 \pm 6.9$ & $109.1 \pm 8.2$ & $2.9(0.0,5.9)^{*}$ & $-4.3(-7.7,-1.0)^{*}$ \\
\hline Countermovement jump test $(\mathrm{cm})$ & $25.5 \pm 3.7$ & $25.0 \pm 4.0$ & $-0.43(-1.1,0.2)$ & $24.5 \pm 3.1$ & $24.6 \pm 3.2$ & $0.1(-0.9,1.2)$ & $-0.55(-1.7,0.6)$ \\
\hline Triple-hop for distance test $(\mathrm{cm})$ & $523 \pm 55.1$ & $506 \pm 52.5$ & $-17.1(-26.1,-8.2)^{*}$ & $527 \pm 53.3$ & $525 \pm 43.0$ & $-1.5(-18.7,15.7)$ & $-15.6(-34.6,3.3)$ \\
\hline Illinois agility test $(\mathrm{s})^{\dagger}$ & $17.43 \pm 0.89$ & $17.50 \pm 0.83$ & $0.06(-0.08,0.21)$ & $17.39 \pm 0.71$ & $17.20 \pm 0.83$ & $-0.20(-.34,-.05)^{*}$ & $0.26(.06, .46)^{*}$ \\
\hline \multicolumn{8}{|l|}{ Sprint test $(\mathrm{s})^{\dagger}$} \\
\hline $10 \mathrm{~m}$ & $2.02 \pm 0.11$ & $2.02 \pm 0.12$ & $-0.01(-0.03,0.02)$ & $2.00 \pm 0.08$ & $2.01 \pm 0.10$ & $0.004(-.02, .03)$ & $-0.01(-.05, .03)$ \\
\hline $20 \mathrm{~m}$ & $3.58 \pm 0.19$ & $3.57 \pm 0.23$ & $0.003(-0.03,0.03)$ & $3.52 \pm 0.15$ & $3.52 \pm 0.17$ & $0.004(-.03, .04)$ & $0.00(-.05, .05)$ \\
\hline
\end{tabular}


Values are mean \pm standard deviation. CI denotes confidence interval.

* Significant difference at $\mathrm{P}<0.05$.

$\dagger$ Data analysed for 17 players in the control group and 22 players in the intervention group. 
4 teams eligible for participation, including 73 players

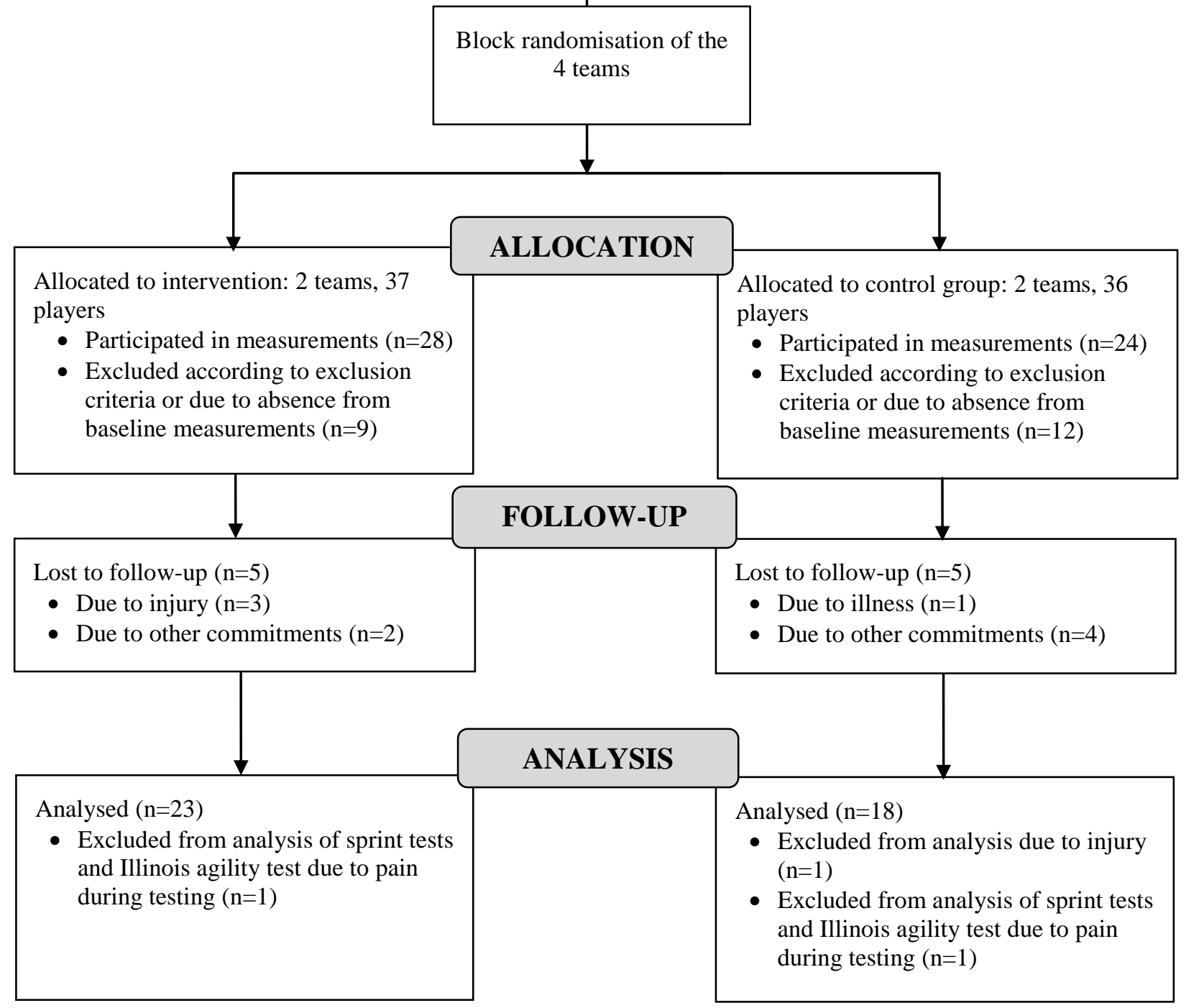

Fig. 1 Flow chart over the inclusion and exclusion of players in the trial. 


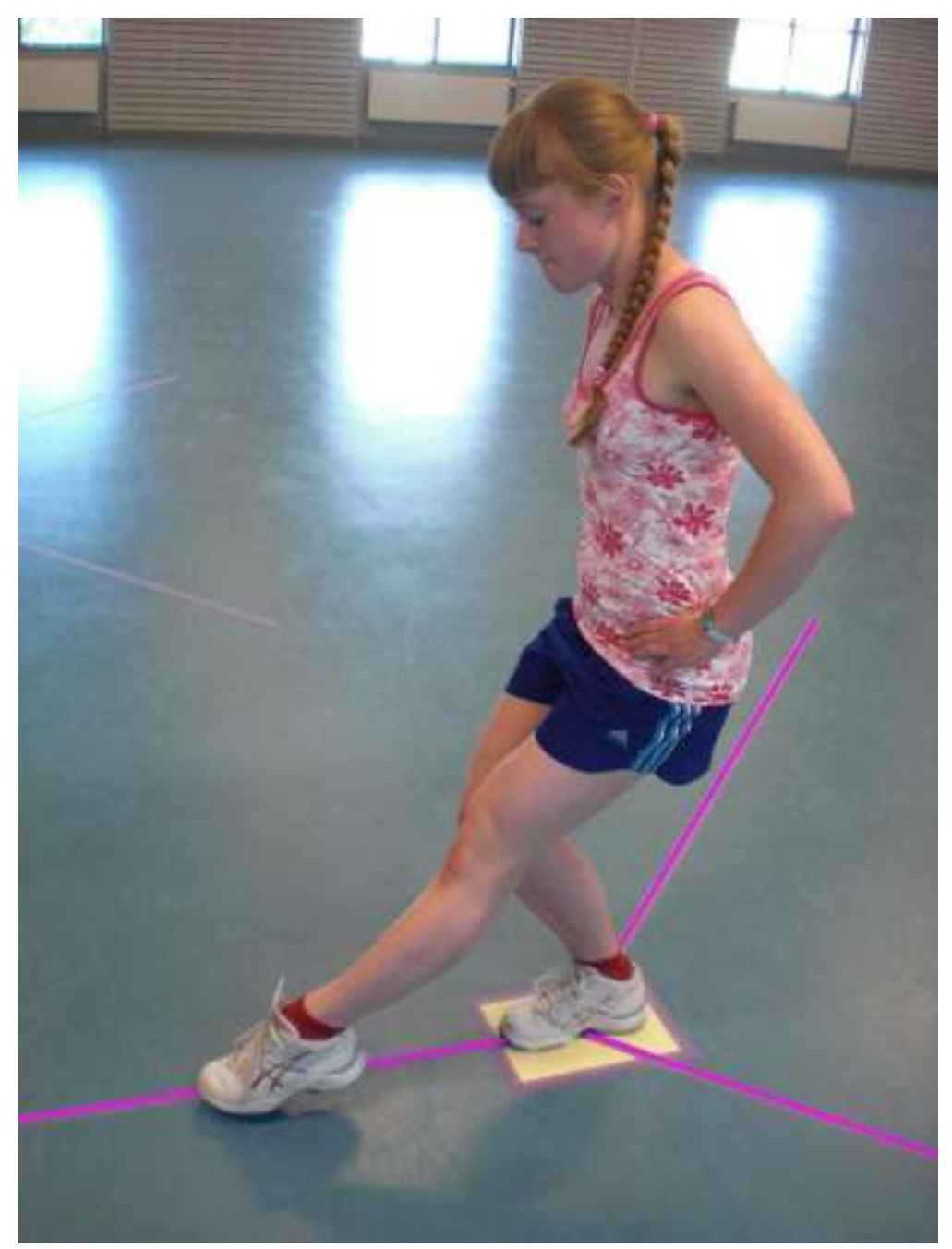

Fig. 2 Performance of the star excursion balance test on the right leg in the anterior direction. 


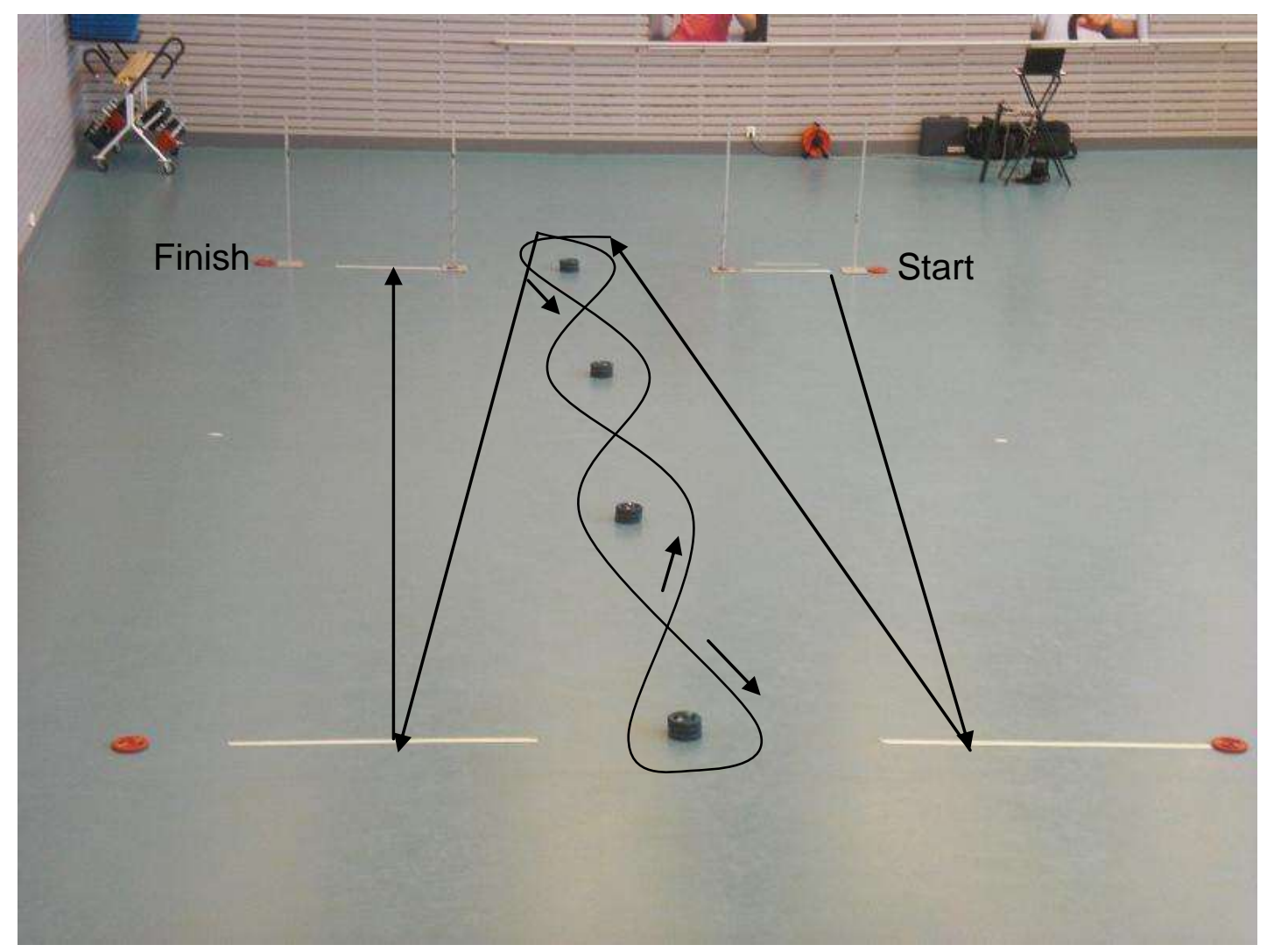

Fig. 3 Overview of the modified Illinois agility test. The length of the course was 10 meters and the width 5 meters. Players started with one foot in front of the other at the starting line, and at command they sprinted through the course. When turning after the first 10 meter sprint, and again prior to the last 10 meter sprint to the finish line, the player touched the ground with one hand to ensure that the line was crossed. 